\title{
Challenging the obesity paradox: extreme obesity and COPD mortality in the SUMMIT trial
}

\author{
Emily P. Brigham $\mathbb{\mathbb { D }}^{1}$, Julie A. Anderson $\mathbb{Q}^{2}$, Robert D. Brook ${ }^{3}$, Peter M.A. Calverley ${ }^{4}$, Bartolome R. Celli $\mathbb{D}^{5}$, \\ Nicholas J. Cowans ${ }^{6}$, Courtney Crim $^{7}$, James E. Diserens ${ }^{6}$, Fernando J. Martinez ${ }^{8}$, Meredith C. McCormack ${ }^{1}$, \\ David E. Newby ${ }^{9}$, Julie Yates ${ }^{7}$, Jorgen Vestbo $\mathbb{B}^{10}$, Tianshi David Wu $\mathbb{C}^{11}$ and Robert A. Wise $\mathbb{C}^{1}$
}

${ }^{1}$ Division of Pulmonary and Critical Care Medicine, Johns Hopkins Medicine, Baltimore, MD, USA. ${ }^{2}$ Research and Development, GlaxoSmithKline, Stockley Park, UK. ${ }^{3}$ Division of Cardiovascular Diseases, Wayne State University, Detroit, MI, USA. ${ }^{4}$ Dept of Medicine, Clinical Sciences Centre, University of Liverpool, University Hospital Aintree, Liverpool, UK. ${ }^{5}$ Division of Pulmonary and Critical Care Medicine, Brigham and Women's Hospital, Harvard Medical School, Boston, MA, USA. 'Statistics and Programming, Veramed Ltd, Twickenham, UK. ${ }^{7}$ Research and Development, GlaxoSmithKline, Research Triangle Park, NC, USA. ${ }^{8}$ Division of Pulmonary and Critical Care Medicine, Weill Cornell Medicine, New York, NY, USA. ${ }^{9}$ Centre for Cardiovascular Science, University of Edinburgh, Edinburgh, UK. ${ }^{10}$ Division of Infection, Immunity and Respiratory Medicine, Manchester Academic Health Sciences Centre, The University of Manchester and Manchester University NHS Foundation Trust, Manchester, UK. ${ }^{11}$ Section of Pulmonary, Critical Care, and Sleep Medicine, Baylor College of Medicine, Houston, TX, USA.

Corresponding author: Emily P. Brigham (ebrigham@jhmi.edu)

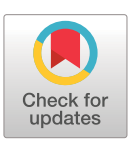

Copyright @The authors 2021

This version is distributed unde the terms of the Creative Commons Attribution NonCommercial Licence 4.0. For commercial reproduction rights and permissions contact permissions@ersnet.org

This article has supplementary material available from openres.ersjournals.com

Received: 2 Dec 2020 Accepted: 1 May 2021

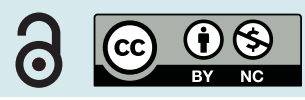

Shareable abstract (@ERSpublications)

In a population with moderate COPD, at heightened cardiovascular risk and containing a substantial proportion of individuals with BMI $\geqslant 40 \mathrm{~kg} / \mathrm{m}^{2}$, BMI and mortality demonstrate a U-shaped (rather than J-shaped) relationship https://bit.ly/3hDztl6

Cite this article as: Brigham EP, Anderson JA, Brook RD, et al. Challenging the obesity paradox: extreme obesity and COPD mortality in the SUMMIT trial. ERJ Open Res 2021; 7: 00902-2020 [DOI: 10.1183/23120541.00902-2020].

\section{Abstract}

Populations with COPD demonstrate higher survival in overweight and obese compared with normal weight; the "obesity paradox". Relationships in less-severe COPD are unclear, as is the impact of cardiovascular risk, and few studies include individuals at extremes of obesity.

We examined the relationship between body mass index (BMI; defined as underweight: $<20 \mathrm{~kg} \cdot \mathrm{m}^{-2}$, normal: $20-25 \mathrm{~kg} \cdot \mathrm{m}^{-2}$, overweight: $25-<30 \mathrm{~kg} \cdot \mathrm{m}^{-2}$, obese class I: $30-<35 \mathrm{~kg} \cdot \mathrm{m}^{-2}$, class II: $35-$ $<40 \mathrm{~kg} \cdot \mathrm{m}^{-2}$ and class III: $\left.\geqslant 40 \mathrm{~kg} \cdot \mathrm{m}^{-2}\right)$, morbidity, and mortality in the SUMMIT trial population $(\mathrm{n}=16$ 485), characterised by moderate COPD and heightened cardiovascular risk with a substantial proportion with class III obesity. The association between BMI category and time to event was modelled via proportional hazards (reference normal weight) adjusted for demographics and cardiorespiratory disease.

Consistent with the paradox, underweight individuals demonstrated higher mortality (hazard ratio (HR) 1.31 (95\% CI 1.04-1.64)), with lower mortality among overweight (HR 0.62 (95\% CI 0.52-0.73)) and obese class I (HR 0.75 (95\% CI 0.62-0.90)). However, mortality increased in obese class III (HR 1.36 (95\% CI 1.00-1.86)). Death was primarily attributable to cardiovascular causes.

Within a large, multinational cohort with moderate COPD and increased cardiovascular risk, the phenomenon of reduced mortality with obesity did not persist at BMI $>40 \mathrm{~kg} \cdot \mathrm{m}^{-2}$, suggesting that obesity may not remain protective at the extremes in this population.

\section{Introduction}

Previous studies in COPD populations demonstrate improved survival in overweight and obese compared with normal weight individuals, and increased mortality in the underweight [1, 2]. This reverse "J-shaped" curve is referred to as the "obesity paradox", and has been described in several other chronic disease states [3-5]. In the general population, however, the relationship between body mass index (BMI) and survival is "U-shaped" with an increase in mortality noted both with underweight compared with normal weight individuals, and again with increasing BMI/obesity [6, 7]. It remains unclear why the "U-shaped" curve 
has not been reflected in populations with COPD. Several hypotheses are proposed to explain this discrepancy, including sparse data on patients with COPD at the extremes of obesity.

Furthermore, the paradox has been most apparent in patients with severe disease (defined by lower forced expiratory volume in $\left.1 \mathrm{~s}\left(\mathrm{FEV}_{1}\right)\right)$ [2, 8]. Whether the paradox applies to patients with milder disease is uncertain. Relationships between BMI and cause-specific mortality in COPD are largely undefined, and associations with morbidity in the same population is often unexplored. Cardiovascular disease is a common comorbidity in COPD [9, 10] and a major cause of death [11, 12], but cardiovascular risk is often not described in studies of the obesity paradox.

The SUMMIT (Study to Understand Mortality and Morbidity In COPD) trial was conducted in a large, international population with moderate COPD at heightened cardiovascular risk [13]. Over 16000 patients were randomised to inhaler therapies including fluticasone furoate and/or vilanterol, with similar mortality rates regardless of treatment assignment. Standardised adjudication of all deaths and cardiovascular events was performed. COPD exacerbations were captured as protocol-defined events. A substantial number of individuals (over 500) had class III obesity (BMI $\geqslant 40 \mathrm{~kg} \cdot \mathrm{m}^{-2}$ ), presenting an ideal opportunity to investigate the obesity paradox over a wide range of BMI. Because cause of death and cardiopulmonary morbidity events were also captured as outcomes, we additionally investigated the association between BMI category and cause-specific mortality rates, COPD exacerbation rates, and cardiovascular event rates.

\section{Methods}

\section{Study subjects}

All participants in the SUMMIT trial [13] in the intent-to-treat population were included in the present analysis, with basic eligibility criteria including: age 40-80 years, moderate COPD (defined as $\mathrm{FEV}_{1}$ / forced vital capacity (FVC) $\leqslant 0.70$, and $\mathrm{FEV}_{1}$ of $50-70 \%$ of predicted values [14, 15], at least 10 pack-years smoking history, and modified Medical Research Council (mMRC) score of 2 or greater), and history of or risk factors for cardiovascular disease. A complete listing of eligibility criteria is published elsewhere [16] All participants in the current analysis provided written, informed consent for trial participation. The SUMMIT trial was approved by local ethics committees and conducted in accordance with the Declaration of Helsinki and Good Clinical Practice guidelines.

\section{Study design}

We present a post hoc analysis of trial results. As detailed in previous trial descriptions [13, 16], 16485 patients from 43 countries were included in the intention-to-treat efficacy population, and randomised 1:1:1:1 to once-daily inhaled placebo, fluticasone furoate $(100 \mu \mathrm{g})$, vilanterol (25 $\mu \mathrm{g})$, or the combination of fluticasone and vilanterol. Participants were seen every 3 months after randomisation to document vital status and adverse events. The trial opened enrolment on January 24, 2011 and completed data collection July 15, 2015.

BMI was obtained at enrolment. Overweight (BMI 25-<30 kg $\cdot \mathrm{m}^{-2}$ ), obese class I (BMI 30-<35 $\mathrm{kg} \cdot \mathrm{m}^{-2}$ ), class II (BMI $35-<40 \mathrm{~kg} \cdot \mathrm{m}^{-2}$ ) and class III $\left(\mathrm{BMI} \geqslant 40 \mathrm{~kg} \cdot \mathrm{m}^{-2}\right.$ ) were defined by World Health Organization (WHO) criteria. Normal weight was considered BMI $20-<25 \mathrm{~kg} \cdot \mathrm{m}^{-2}$, with underweight as $<20 \mathrm{~kg} \cdot \mathrm{m}^{-2}$ and separately as $<18.5 \mathrm{~kg} \cdot \mathrm{m}^{-2}$ (sensitivity analysis, WHO criteria [17]).

The primary outcome in this analysis and in the original trial was all-cause mortality, defined as time to on- and post-treatment death. A secondary outcome of cause-specific mortality was adjudicated by a clinical end-point committee using a combination of study data, death certificates, autopsy findings, and health records. Respiratory morbidity outcomes included on-treatment moderate COPD exacerbations, defined by symptoms requiring antibiotic or systemic corticosteroid administration, on-treatment severe COPD exacerbations, defined by deterioration requiring hospital admission, and pneumonia, defined by a comprehensive list of pneumonia MedDRA-preferred terms applied to investigator-reported adverse events [18]. A predefined on-treatment composite cardiovascular event outcome included cardiovascular death, myocardial infarction, unstable angina, stroke, or transient ischaemic attack.

\section{Analysis}

Variable distribution was examined and summary statistics calculated within each BMI category. Using the normal weight category as reference, the association between BMI category and time to event was evaluated using Cox proportional hazards modelling, with competing risk methods applied for cause-specific mortality outcomes. Analyses were adjusted for age, sex, region, race, ischaemic heart disease indicator, vascular disease indicator, smoking status, cardiovascular entry criteria (history and risk 
by age), previous COPD exacerbations, per cent predicted $\mathrm{FEV}_{1}$, treatment arm and BMI (categorical) [13]. Interaction between treatment arm and BMI (categorical) was tested and was not significant.

Analyses were completed using SAS version 9.4 (SAS Institute Inc., Cary, NC, USA). Statistical significance was defined as $\mathrm{p}<0.05$.

Results

In total, 16485 participants were included in the analysis. A quarter (26.1\%) of the sample were classified as normal weight $(n=4306)$, with $6.7 \%(n=1111)$ underweight, $34.3 \%$ overweight $(n=5662)$, and $32.8 \%$ obese $(n=5406)$. Baseline characteristics stratified by BMI category are shown in table 1 and table 1S. Age, lung function, and treatment assignment were similar across categories. Obese groups tended towards a higher proportion of women, white participants, US origin, and prevalent $(\geqslant 2)$ COPD exacerbations in the year prior to enrolment. Obese groups also demonstrated higher diabetes prevalence (including diabetes with target organ disease), hypercholesterolaemia, and hypertension, though curiously lower prevalence of previous stroke. Conversely, normal and underweight strata tended towards a higher proportion of Asian race and origin, higher current smoking, and higher rates of peripheral arterial disease. Obese individuals were more likely to report use of any of the long-acting inhaler therapies ( $\beta$-agonist, muscarinic antagonist, inhaled corticosteroids), and most reported cardiovascular therapies (table $2 \mathrm{~S}$ ).

Compared with the predefined normal weight strata (BMI $20-<25 \mathrm{~kg} \cdot \mathrm{m}^{-2}$ ), overweight and class I obese individuals demonstrated 38\% (95\% CI 27-48\%) and 25\% (95\% CI 10-38\%) lower risk of death during the duration of the trial, respectively (figure 1). Conversely, individuals who were underweight demonstrated a 31\% (95\% CI 4-64\%) increase in the risk of death (with similar rates when $<20 \mathrm{~kg} \cdot \mathrm{m}^{-2}$ was split further into categories of underweight II $\left(<18.5 \mathrm{~kg} \cdot \mathrm{m}^{-2}\right)$ and underweight I $\left(18.5-<20 \mathrm{~kg} \cdot \mathrm{m}^{-2}\right)$, table 4 S), and individuals with class III obesity demonstrated a 36\% (95\% CI 0-86\%) increase in the risk of death compared with those with a normal BMI (figure 1). In all BMI strata, rates of death due to cardiovascular disease were higher than those attributable to respiratory causes (table 2 and table 4S). Respiratory deaths contributed more to mortality in the underweight (where $2.2 \%$ of patients died of respiratory causes; HR 1.44, 95\% CI 0.86-2.41) than the obese class III category (where 1.0\% of patients died; HR 1.31, 95\% CI 0.54-3.16). Being overweight compared to having a lower BMI was associated with a decreased hazard of both respiratory (HR 0.51, 95\% CI 0.32-0.81) and cardiovascular (HR 0.69, 95\% CI 0.53-0.88) mortality.

Regarding morbidity, being overweight was associated with a lower risk of severe COPD exacerbation (HR 0.85, 95\% CI 0.73-0.98) or pneumonia (HR 0.76, 95\% CI 0.63-0.91) during treatment, while class II obesity was associated with a higher risk of moderate/severe COPD exacerbation (HR 1.14, 95\% CI 1.011.28). Underweight was conversely associated with a higher risk of pneumonia (HR 1.33, 95\% CI 1.051.67) compared to normal weight. No other significant, unique associations between BMI strata and moderate/severe or severe COPD exacerbations or cardiovascular events were noted in the main analyses (table 3) or sensitivity analyses (table 5S).

\section{Discussion}

Data from the large, international SUMMIT trial including patients with moderate COPD at heightened cardiovascular risk demonstrates that BMI is associated with risk of all-cause mortality at the extremes; specifically, among underweight (BMI $<20 \mathrm{~kg} \cdot \mathrm{m}^{-2}$ ) and obese class III (BMI $\geqslant 40 \mathrm{~kg} \cdot \mathrm{m}^{-2}$ ). Moderate levels of obesity and overweight are associated with lower risk of death. Risk of death due to respiratory causes is highest among underweight individuals, though the leading cause of death in all BMI categories is cardiovascular, with the highest risk among obese class III. A "U-shaped" curve (with a protective association with overweight) was not consistently identified for morbidity outcomes.

The findings support and extend several studies demonstrating that underweight is a substantial risk factor for mortality in patients with COPD [1, 8, 19-21]. It has been argued that there is reverse causation with increasing severity of illness coinciding with weight loss and underweight status [20]. While the ability of nutritional supplementation and weight gain to reduce COPD mortality remains unclear [22, 23], the relationship between underweight and mortality exists even within patients with mild or moderate disease [8], suggesting that disease severity alone may not account for increased mortality among underweight. Furthermore, findings in the SUMMIT population are consistent with prior studies demonstrating a protective association between overweight and obesity and COPD mortality [2, 24-26]. The protective associations with higher BMI are typically strongest with increasing disease severity [8], and are reflected here in a population with moderate disease. In all categories, cardiovascular mortality predominated, 
TABLE 1 Baseline characteristics of study participants by body mass index (BMI) category

\begin{tabular}{|c|c|c|c|c|c|c|}
\hline & $\begin{array}{l}\text { Underweight } \\
<20 \mathrm{~kg} \cdot \mathrm{m}^{-2}\end{array}$ & $\begin{array}{c}\text { Normal } \\
20-<25 \mathrm{~kg} \cdot \mathrm{m}^{-2}\end{array}$ & $\begin{array}{l}\text { Overweight } \\
25-<30 \mathrm{~kg} \cdot \mathrm{m}^{-2}\end{array}$ & $\begin{array}{l}\text { Class I obesity } \\
30-<35 \mathrm{~kg} \cdot \mathrm{m}^{-2}\end{array}$ & $\begin{array}{l}\text { Class II obesity } \\
35-<40 \mathrm{~kg} \cdot \mathrm{m}^{-2}\end{array}$ & $\begin{array}{l}\text { Class III obesity } \\
\geqslant 40 \mathrm{~kg} \cdot \mathrm{m}^{-2}\end{array}$ \\
\hline Subjects $n$ & 1111 & 4306 & 5662 & 3452 & 1367 & 587 \\
\hline \multicolumn{7}{|l|}{ Demographics } \\
\hline BMI $\left(\mathrm{kg} \cdot \mathrm{m}^{-2}\right)$ & $18.3 \pm 1.3$ & $22.9 \pm 1.4$ & $27.4 \pm 1.4$ & $32.1 \pm 1.4$ & $37.0 \pm 1.4$ & $44.0 \pm 4.0$ \\
\hline Age years & $65.4 \pm 8.4$ & $65.8 \pm 8.0$ & $65.5 \pm 7.9$ & $65.0 \pm 7.5$ & $63.4 \pm 7.8$ & $62.3 \pm 7.8$ \\
\hline Female & $229(21 \%)$ & $941(22 \%)$ & $1373(24 \%)$ & $946(27 \%)$ & $455(33 \%)$ & $252(43 \%)$ \\
\hline \multicolumn{7}{|l|}{ Race } \\
\hline White & $468(42 \%)$ & $2941(68 \%)$ & 4841 (85\%) & $3236(94 \%)$ & $1314(96 \%)$ & 557 (95\%) \\
\hline Asian & $625(56 \%)$ & $1262(29 \%)$ & $694(12 \%)$ & $126(4 \%)$ & $13(<1 \%)$ & $3(<1 \%)$ \\
\hline Other & $18(2 \%)$ & $103(2 \%)$ & $127(2 \%)$ & $90(3 \%)$ & $40(3 \%)$ & $27(5 \%)$ \\
\hline \multicolumn{7}{|l|}{ Region } \\
\hline USA & $75(7 \%)$ & $443(10 \%)$ & $859(15 \%)$ & $655(19 \%)$ & $344(25 \%)$ & $214(36 \%)$ \\
\hline Europe & $340(31 \%)$ & $2322(54 \%)$ & $3700(65 \%)$ & $2365(69 \%)$ & $889(65 \%)$ & $302(51 \%)$ \\
\hline Asia & $625(56 \%)$ & $1245(29 \%)$ & $681(12 \%)$ & $120(3 \%)$ & $12(<1 \%)$ & $3(<1 \%)$ \\
\hline Rest of world & $71(6 \%)$ & $296(7 \%)$ & $422(7 \%)$ & $312(9 \%)$ & $122(9 \%)$ & $68(12 \%)$ \\
\hline Current smokers & $617(56 \%)$ & $2281(53 \%)$ & $2589(46 \%)$ & $1389(40 \%)$ & $570(42 \%)$ & $232(40 \%)$ \\
\hline Smoking history (pack-years) & $39.1 \pm 23.6$ & $40.4 \pm 23.4$ & $40.2 \pm 23.8$ & $41.8 \pm 25.1$ & $42.4 \pm 27.1$ & $41.9 \pm 26.3$ \\
\hline \multicolumn{7}{|l|}{ Lung function } \\
\hline Post-BD FEV ${ }_{1}(\mathrm{~L})$ at screening & $1.5 \pm 0.4$ & $1.6 \pm 0.4$ & $1.7 \pm 0.4$ & $1.7 \pm 0.4$ & $1.7 \pm 0.4$ & $1.7 \pm 0.4$ \\
\hline $\begin{array}{l}\% \text { Predicted post-BD } \mathrm{FEV}_{1} \text { at } \\
\text { screening }\end{array}$ & $60.0 \pm 6.3$ & $59.8 \pm 6.2$ & $59.8 \pm 6.1$ & $59.4 \pm 5.9$ & $59.2 \pm 6.1$ & $58.9 \pm 6.1$ \\
\hline $\begin{array}{l}\mathrm{FEV}_{1} \text { reversibility (\% of pre-BD FEV } \mathrm{F}_{1} \text { ) } \\
\text { at screening }\end{array}$ & $7.6 \pm 12.2$ & $8.1 \pm 12.2$ & $8.1 \pm 11.6$ & $8.0 \pm 12.0$ & $9.0 \pm 12.4$ & $9.0 \pm 12.2$ \\
\hline \multicolumn{7}{|c|}{ Pre-study COPD exacerbations in 12 months before study } \\
\hline 0 & $717(65 \%)$ & $2675(62 \%)$ & $3390(60 \%)$ & $2065(60 \%)$ & $828(61 \%)$ & $346(59 \%)$ \\
\hline 1 & $233(21 \%)$ & $1009(23 \%)$ & $1418(25 \%)$ & $888(26 \%)$ & $338(25 \%)$ & $134(23 \%)$ \\
\hline$\geqslant 2$ & $161(14 \%)$ & $622(14 \%)$ & $854(15 \%)$ & $499(14 \%)$ & $201(15 \%)$ & $107(18 \%)$ \\
\hline \multicolumn{7}{|l|}{ Cardiovascular inclusion criteria\# } \\
\hline \multicolumn{7}{|l|}{ Manifest disease } \\
\hline Coronary artery disease & $445(40 \%)$ & $2056(48 \%)$ & $2951(52 \%)$ & $1868(54 \%)$ & $745(54 \%)$ & $314(53 \%)$ \\
\hline Peripheral arterial disease & $245(22 \%)$ & $841(20 \%)$ & $1096(19 \%)$ & $629(18 \%)$ & $234(17 \%)$ & $100(17 \%)$ \\
\hline Previous stroke & $147(13 \%)$ & $439(10 \%)$ & $546(10 \%)$ & $309(9 \%)$ & $108(8 \%)$ & $46(8 \%)$ \\
\hline Previous myocardial infarction & $144(13 \%)$ & $653(15 \%)$ & $967(17 \%)$ & $666(19 \%)$ & $246(18 \%)$ & $98(17 \%)$ \\
\hline Diabetes with target organ disease & $58(5 \%)$ & $237(6 \%)$ & $458(8 \%)$ & $414(12 \%)$ & $230(17 \%)$ & $106(18 \%)$ \\
\hline \multicolumn{7}{|l|}{ At risk } \\
\hline Hypercholesterolaemia & $547(49 \%)$ & $2467(57 \%)$ & $3579(63 \%)$ & $2300(67 \%)$ & $906(66 \%)$ & $391(67 \%)$ \\
\hline Hypertension & $833(75 \%)$ & $3506(81 \%)$ & $4931(87 \%)$ & $3183(92 \%)$ & $1274(93 \%)$ & $538(92 \%)$ \\
\hline Diabetes mellitus & $200(18 \%)$ & $818(19 \%)$ & $1395(25 \%)$ & $1103(32 \%)$ & $588(43 \%)$ & $272(46 \%)$ \\
\hline Peripheral arterial disease & $130(12 \%)$ & $420(10 \%)$ & $564(10 \%)$ & $309(9 \%)$ & $100(7 \%)$ & $54(9 \%)$ \\
\hline \multicolumn{7}{|l|}{ SUMMIT treatment assignment } \\
\hline Fluticasone furoate & $298(27 \%)$ & $1086(25 \%)$ & $1420(25 \%)$ & $860(25 \%)$ & $336(25 \%)$ & $135(23 \%)$ \\
\hline Vilanterol & $280(25 \%)$ & $1061(25 \%)$ & $1400(25 \%)$ & $881(26 \%)$ & $325(24 \%)$ & $171(29 \%)$ \\
\hline Fluticasone furoate/vilanterol & $280(25 \%)$ & $1052(24 \%)$ & $1437(25 \%)$ & $857(25 \%)$ & $344(25 \%)$ & $151(26 \%)$ \\
\hline Placebo & $253(23 \%)$ & $1107(26 \%)$ & $1405(25 \%)$ & $854(25 \%)$ & $362(26 \%)$ & $130(22 \%)$ \\
\hline
\end{tabular}




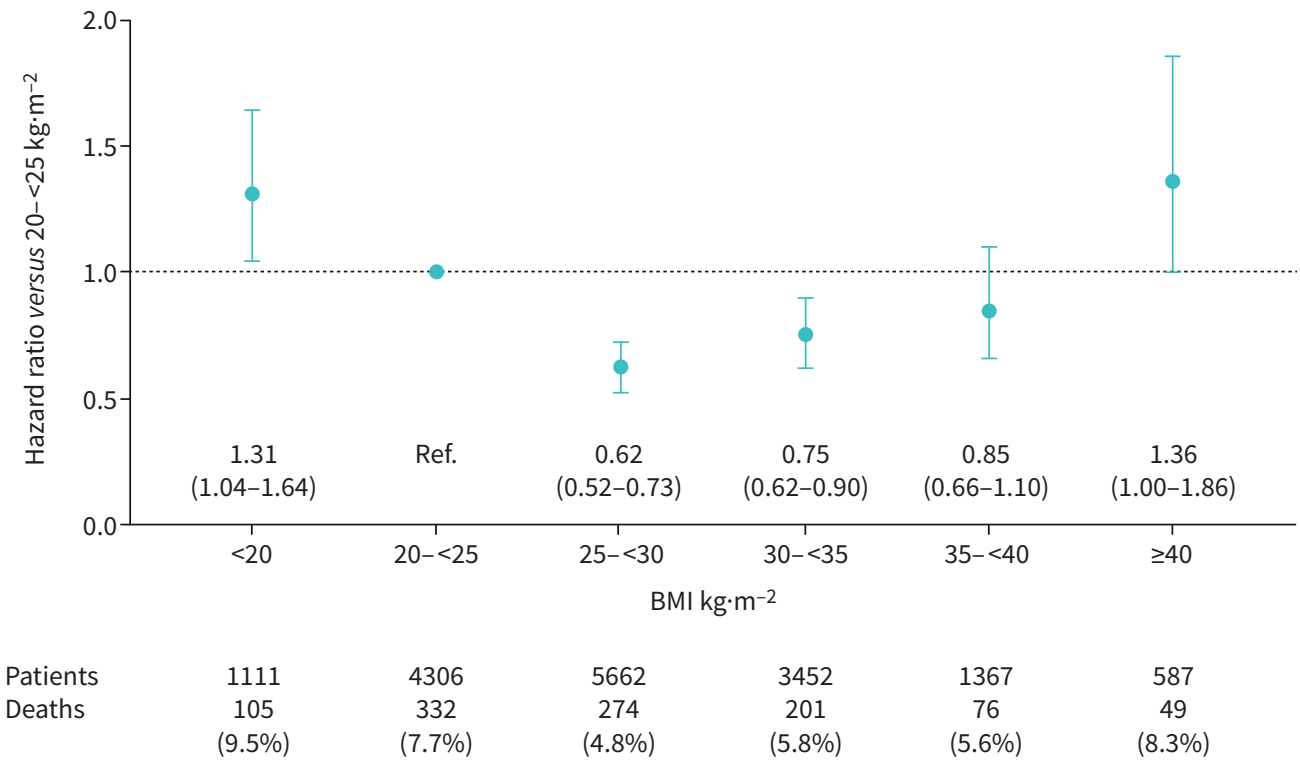

FIGURE 1 All-cause mortality by body mass index (BMI) category. Adjusted for age, sex, region, race, ischaemic heart disease, vascular disease, smoking status, cardiovascular history/risk, previous COPD exacerbations, $\%$ predicted forced expiratory volume in $1 \mathrm{~s}$, treatment arm and BMI.

consistent with population studies demonstrating cardiovascular disease as a leading cause of death in patients with COPD [11, 12, 27] and reasonable in this population at heightened cardiovascular risk.

Because of the large number of participants in the trial, there were a substantial number with class III obesity. Although class I obesity was associated with a lower mortality risk, individuals with class III obesity demonstrated increased risk for mortality. Indeed, weight gain in obese patients has previously been associated with increased mortality in individuals with severe COPD [28]. While overall increased mortality rates above $40 \mathrm{~kg} \cdot \mathrm{m}^{-2}$ might be expected based on well-known associations with hypertension, hypercholesterolaemia, and diabetes, the prevalence of these conditions were similar between BMI classes II and III at trial initiation, suggesting a potential alternative explanation. Other comorbidities not captured in the SUMMIT data may play a role. For example, class III obesity is also associated with higher rates of sleep apnoea [29], which is linked to increased mortality and is an important comorbidity in COPD [30, 31]. Further, COPD phenotype may play a role in BMI-mortality relationships; patients with an emphysematous phenotype are more likely to be underweight, whereas patients with a chronic bronchitis phenotype are more likely to be overweight [32]. While these diagnoses are not mutually exclusive, it is possible that disease phenotypes are partially responsible for the associations noted.

TABLE 2 Total on- and post-treatment cause-specific mortality by body mass index (BMI) category

\begin{tabular}{|c|c|c|c|c|c|c|}
\hline & $\begin{array}{l}\text { Underweight } \\
<20 \mathrm{~kg} \cdot \mathrm{m}^{-2}\end{array}$ & $\begin{array}{c}\text { Normal } \\
20-<25 \mathrm{~kg} \cdot \mathrm{m}^{-2}\end{array}$ & $\begin{array}{c}\text { Overweight } \\
25-<30 \mathrm{~kg} \cdot \mathrm{m}^{-2}\end{array}$ & $\begin{array}{c}\text { Class I obesity } \\
30-<35 \mathrm{~kg} \cdot \mathrm{m}^{-2}\end{array}$ & $\begin{array}{l}\text { Class II obesity } \\
35-<40 \mathrm{~kg} \cdot \mathrm{m}^{-2}\end{array}$ & $\begin{array}{c}\text { Class III obesity } \\
\geqslant 40 \mathrm{~kg} \cdot \mathrm{m}^{-2}\end{array}$ \\
\hline Subjects $\mathrm{n}$ & 1111 & 4306 & 5662 & 3452 & 1367 & 587 \\
\hline \multicolumn{7}{|l|}{ Respiratory mortality } \\
\hline Deaths (\%) & $24(2.2 \%)$ & $49(1.1 \%)$ & $27(0.5 \%)$ & $23(0.7 \%)$ & $8(0.6 \%)$ & $6(1.0 \%)$ \\
\hline Hazard ratio $(95 \% \mathrm{Cl})$ & $1.44(0.86-2.41)$ & Ref. & $0.51(0.32-0.81)$ & $0.77(0.46-1.30)$ & $0.80(0.37-1.72)$ & $1.31(0.54-3.16)$ \\
\hline \multicolumn{7}{|l|}{ Cardiovascular mortality } \\
\hline Deaths (\%) & $41(3.7 \%)$ & $132(3.1 \%)$ & $119(2.1 \%)$ & $94(2.7 \%)$ & $35(2.6 \%)$ & $24(4.1 \%)$ \\
\hline Hazard ratio $(95 \% \mathrm{Cl})$ & $1.30(0.90-1.87)$ & Ref. & $0.69(0.53-0.88)$ & $0.90(0.68-1.19)$ & $1.04(0.71-1.53)$ & $1.87(1.19-2.94)$ \\
\hline
\end{tabular}

Hazard ratio $(95 \% \mathrm{Cl})$ per Cox proportional hazards. Adjusted model accounts for age, sex, region, race, ischaemic heart disease indicator, vascular disease indicator, smoking status, cardiovascular entry criteria (history and risk by age), previous COPD exacerbations, \% predicted forced expiratory volume in $1 \mathrm{~s}$, treatment arm and BMI. 
TABLE 3 On-treatment system-specific morbidity by body mass index (BMI) categories

\begin{tabular}{|c|c|c|c|c|c|c|}
\hline & $\begin{array}{l}\text { Underweight } \\
<20 \mathrm{~kg} \cdot \mathrm{m}^{-2} \\
(n=1111)\end{array}$ & $\begin{array}{c}\text { Normal } \\
20-<25 \mathrm{~kg} \cdot \mathrm{m}^{-2} \\
(\mathrm{n}=4306)\end{array}$ & $\begin{array}{c}\text { Overweight } \\
25-<30 \mathrm{~kg} \cdot \mathrm{m}^{-2} \\
(n=5662)\end{array}$ & $\begin{array}{l}\text { Class I obesity } \\
30-<35 \mathrm{~kg} \cdot \mathrm{m}^{-2} \\
(\mathrm{n}=3452)\end{array}$ & $\begin{array}{l}\text { Class II obesity } \\
35-<40 \mathrm{~kg} \cdot \mathrm{m}^{-2} \\
\quad(\mathrm{n}=1367)\end{array}$ & $\begin{array}{l}\text { Class III obesity } \\
\begin{array}{c}\geqslant 40 \mathrm{~kg} \cdot \mathrm{m}^{-2} \\
(\mathrm{n}=587)\end{array}\end{array}$ \\
\hline \multicolumn{7}{|c|}{ Moderate/severe COPD exacerbation ${ }^{\#}$} \\
\hline Events (\%) & $325(29.3 \%)$ & $1206(28.0 \%)$ & $1551(27.4 \%)$ & $1005(29.1 \%)$ & $429(31.4 \%)$ & $188(32.0 \%)$ \\
\hline Hazard ratio $(95 \% \mathrm{Cl})$ & $1.01(0.89-1.14)$ & Ref. & $0.97(0.90-1.05)$ & $1.02(0.93-1.11)$ & $1.14(1.01-1.28)$ & $1.05(0.89-1.23)$ \\
\hline \multicolumn{7}{|c|}{ Severe COPD exacerbation" } \\
\hline Events (\%) & $128(11.5 \%)$ & $367(8.5 \%)$ & $384(6.8 \%)$ & $265(7.7 \%)$ & $105(7.7 \%)$ & $44(7.5 \%)$ \\
\hline Hazard ratio $(95 \% \mathrm{Cl})$ & $1.18(0.96-1.46)$ & Ref. & $0.85(0.73-0.98)$ & $1.02(0.87-1.21)$ & $1.14(0.90-1.43)$ & $1.07(0.77-1.49)$ \\
\hline \multicolumn{7}{|l|}{ Pneumonia } \\
\hline Events (\%) & $106(9.5 \%)$ & $260(6.0 \%)$ & $235(4.2 \%)$ & $153(4.4 \%)$ & $58(4.2 \%)$ & $26(4.4 \%)$ \\
\hline Hazard ratio $(95 \% \mathrm{Cl})$ & $1.33(1.05-1.67)$ & REF. & $0.76(0.63-0.91)$ & $0.83(0.67-1.03)$ & $0.84(0.62-1.14)$ & $0.80(0.52-1.22)$ \\
\hline \multicolumn{7}{|c|}{ Composite cardiovascular events $^{+}$} \\
\hline Events (\%) & $46(4.1 \%)$ & $191(4.4 \%)$ & $231(4.1 \%)$ & $154(4.5 \%)$ & $47(3.4 \%)$ & $19(3.2 \%)$ \\
\hline Hazard ratio $(95 \% \mathrm{Cl})$ & $1.01(0.73-1.40)$ & Ref. & $0.90(0.74-1.10)$ & $0.98(0.78-1.22)$ & $0.88(0.64-1.23)$ & $0.93(0.57-1.50)$ \\
\hline \multicolumn{7}{|c|}{$\begin{array}{l}\text { Hazard ratio }(95 \% \mathrm{Cl}) \text { per Cox proportional hazards. Adjusted model accounts for age, sex, region, race, ischaemic heart disease indicator, vascular } \\
\text { disease indicator, smoking status, cardiovascular entry criteria (history and risk by age), previous COPD exacerbations, \% predicted forced } \\
\text { expiratory volume in } 1 \mathrm{~s} \text {, treatment arm and BMI. ": moderate COPD exacerbations were exacerbation treated with antibiotics and/or systemic } \\
\text { corticosteroids; } 9 \text { : severe COPD exacerbations were those that required hospitalisation; }{ }^{+}: \text {composite cardiovascular events were predefined } \\
\text { secondary end-points, contains myocardial infarction, stroke, transient ischaemic attack, unstable angina, and on-treatment cardiovascular death. }\end{array}$} \\
\hline
\end{tabular}

Few studies in the current literature have examined associations between BMI and COPD morbidity outcomes, although several have combined morbidity and mortality into a single variable [24, 33]. These studies overall demonstrate increased respiratory morbidity in the underweight (i.e. hospitalisations [33], hospital length of stay [24], pneumonia [18]), although at least one previous analysis suggests higher odds of severe COPD exacerbation at the opposite end of the BMI spectrum, class III obesity [34]. Extreme obesity may confer disadvantageous changes in pulmonary function such as increased airway resistance and reduced lung volumes [35], relevant to individuals with COPD with already compromised respiratory mechanics. It is plausible that this may contribute to respiratory morbidity and exacerbations. Interestingly, in the SUMMIT trial population, overweight was associated with a lower risk of pneumonia. This is consistent with previous findings in the TORCH trial [36] demonstrating lower rates of pneumonia in higher BMI groups [18]. Furthermore, overweight was associated with a lower risk of severe COPD exacerbations, but no increased risk was noted in underweight or class III obese populations. In contrast to overweight, lower mortality rates in class I obesity were not matched with reduced morbidity for the measured outcomes, suggesting the potential for an unmeasured morbidity signal. We did not find an association between BMI category and cardiovascular event risk; previous studies of cardiovascular morbidity outcomes in COPD by BMI are sparse, but suggest higher prevalence of heart failure with obesity, though not necessarily stroke or coronary heart disease [34, 37, 38], which comprise the majority of the events captured in the SUMMIT trial. The discordance between morbidity and mortality outcomes in relation to BMI deserves further attention, and the selection of outcomes is important in defining any future nutritional intervention trials.

Strengths include a study design that allowed for longitudinal assessment of a large number of participants including a critical population with obesity class III, limited in previous COPD studies. Patients with severe and very severe COPD were excluded, providing the opportunity to investigate the paradox in a dedicated cohort with less-severe COPD, which may mitigate confounding of lower weight by higher disease severity. Cardiovascular risk was defined, allowing for adjustment but also mitigating competing respiratory risk in cause-specific mortality analyses. Deaths within the study were carefully adjudicated, with high ascertainment of vital status and confidence in primary and secondary outcomes. Ability to define cause-specific morbidity and mortality outcomes in a single population is unique. International representation increases generalisability of results, while precise characterisation of lung function and rigorous assessment of cardiovascular health enhances validity of application among populations with moderate COPD at heightened cardiovascular risk.

Weaknesses are acknowledged. While cardiovascular comorbidities were well defined, additional comorbidities were not captured, limiting assessment of potential contributing factors. Furthermore, the relatively small number of cardiovascular events (compared with all-cause mortality) may have limited 
power to distinguish between BMI groupings. In this study, a BMI of $20 \mathrm{~kg} \cdot \mathrm{m}^{-2}$ was chosen as the lower limit of the normal weight category for primary analyses. This cut-off point may reduce comparability with other disease states, and falls between the BMI of $21 \mathrm{~kg} \cdot \mathrm{m}^{-2}$ in the BODE index [39] and $18.5 \mathrm{~kg} \cdot \mathrm{m}^{-2}$ in WHO guidelines [17] to define at-risk/underweight populations. However, $20 \mathrm{~kg} \cdot \mathrm{m}^{-2}$ has been used in previous studies demonstrating the obesity paradox in populations with COPD [24, 25], and is of proposed benefit in facilitating international comparisons [40]. This approach combined with sensitivity analyses using the cut-off point of BMI $18.5 \mathrm{~kg} \cdot \mathrm{m}^{-2}$, provides increased granularity and generalisability. History of smoking was an inclusion criterion in the trial, and so differential associations among smokers/nonsmokers and resultant selection bias by smoking was not explored [41]. Residual confounding by region may exist. Underweight individuals were more likely to be enrolled in Asia, whereas obese class II/III individuals were more likely enrolled in Europe and the USA, and outcomes may be influenced by local patterns of medical care and exposures. Adjustment for additional covariates not available within the SUMMIT data may provide more precision in estimates, and reveal factors that adjust or modify the obesity-mortality association in the direction of protection or harm. Multi-collinearity was not assessed. While multi-collinearity has the potential to decrease precision and skew estimates, presented crude death rates mirror the adjusted pattern, and variable inclusion was determined on the basis of clinical relevance and aim to isolate direct BMI associations, avoiding mediation and confounding where possible. Further, collider stratification bias should be considered as a partial or complete methodologic explanation for findings of a protective association with obesity, and bears mention and consideration as an alternative to causality [42, 43]. COPD sub-phenotyping, including imaging or symptom data, was not available for further stratification or adjustment. Finally, all patients were selected for inclusion in a randomised controlled trial and may therefore differ from patients in the general population; caution is warranted in application to populations outside of the trial inclusion criteria.

In conclusion, we have demonstrated a U-shaped curve in the association between BMI category and mortality in an international population with moderate COPD at heightened cardiovascular risk. This relationship extends previous studies demonstrating increased risk of mortality in underweight, and a protective association between overweight and moderate obesity. However, we provide evidence supporting recurrence of increased mortality risk with extreme obesity, at BMI $\geqslant 40 \mathrm{~kg} \cdot \mathrm{m}^{-2}$. Understanding the impact of overweight and obesity on COPD is paramount in the context of rising numbers of individuals with COPD [44] and shifts in prevalence of overweight and obesity worldwide [45]. The relationship described emphasises the need to better understand the impact of BMI-driven nutritional supplementation and weight loss interventions when applied to populations with COPD.

Acknowledgements: The authors would like to thank the SUMMIT steering committee, composed of academic experts and employees from GlaxoSmithKline plc., who were responsible for the scientific oversight of the trial, the study design and analysis, and for the review and interpretation of the data.

This study is registered at www.clinicaltrials.gov with identifier number NCT01313676. Information on GSK's data sharing commitments and requesting access to anonymised individual participant data and associated documents can be found at www.clinicalstudydatarequest.com.

Conflict of interest: E.P. Brigham has nothing to disclose. J.A. Anderson is an employee of and owns shares in GSK. R.D. Brook reports personal fees from GSK for a steering committee during the conduct of the study. P.M.A. Calverley reports that he was a member of the SUMMIT Science Committee supported by GSK; and he was paid for the conduct of the SUMMIT study by GSK, was paid for speaking at a company meeting and for advice on study design by AstraZeneca, he advised on development of new trials and has spoken for Boehringer Ingelheim at sponsored meetings, and he has received personal fees for speaking at sponsored meeting from Novartis, outside the submitted work. B.R. Celli reports personal fees from GlaxoSmithKline during the conduct of the study; and personal fees from AstraZeneca, Sanofi Aventis, Chiesi, Novartis, Menarini and Pulmonx outside the submitted work. N.J. Cowans reports this study was funded by GlaxoSmithKline plc.; and he is an employee of Veramed Ltd, a contract research organisation undertaking contracted statistical analyses of respiratory studies funded by GlaxoSmithKline plc. C. Crim is an employee of GSK and holds GSK stocks/shares; this study was funded by GSK (NCT01313676, GSK study number 113782; Study to Understand Mortality and Morbidity In COPD Trial (SUMMIT)). J.E. Diserens reports this study was funded by GlaxoSmithKline plc.; and he is an employee of Veramed Ltd, a contract research organisation undertaking contracted statistical analyses of respiratory studies funded by GlaxoSmithKline plc. F.J. Martinez reports grants from the NHLBI during the conduct of the study; and grants from the National Institutes of Health, personal fees from Continuing Education and Forest Laboratories, other support from Janssen, and personal fees from GlaxoSmithKline, Nycomed/Takeda, AstraZeneca, Boehringer Ingelheim, Bellerophon (formerly Ikaria), Genentech, Novartis, Pearl, Roche, Sunovion, Theravance, CME Incite, Annenberg 
Center for Health Sciences at Eisenhower, Integritas, InThought, the National Association for Continuing Education, Paradigm Medical Communications, LLC, PeerVoice, UpToDate, Haymarket Communications, the Western Society of Allergy and Immunology, Proterixbio (formerly Bioscale), Unity Biotechnology, ConCert Pharmaceuticals, Lucid, Methodist Hospital, Columbia University, Prime Healthcare Ltd, WebMD, PeerView Network, the California Society of Allergy and Immunology, Chiesi and the Puerto Rico Thoracic Society, outside the submitted work. M.C. McCormack reports support from UpToDate outside the submitted work. D.E. Newby reports grants and personal fees from GSK during the conduct of the study. J.C. Yates is an employee of and owns shares in GSK. J. Vestbo was partly reimbursed for his work as Chair of the SUMMIT Steering Committee buy GlaxoSmithKline during the conduct of the study; and reports consultancy for COPD phase 2 and 3 programmes and payment for lectures including service in speaker bureaus from GlaxoSmithKline, Chiesi Pharmaceuticals, Boehringer Ingelheim, Novartis and AstraZeneca, outside the submitted work. T.D. Wu has nothing to disclose. R.A Wise reports grants and personal fees from GlaxoSmithKline during the conduct of the study; grants and personal fees from AstraZeneca/Medimmune and Boehringer Ingelheim, personal fees from Contrafect, Pulmonx, Roche/Genentech, Spiration, Sunovion, Pearl Therapeutics, Merck, Circassia, Pneuma, Verona, Bonti, Denali, Aradigm, Mylan, Theravance, Propeller Health, Kiniksa and Syneos, outside the submitted work.

Support statement: This study was funded by GlaxoSmithKline plc. (HZC113782). Funding information for this article has been deposited with the Crossref Funder Registry.

\section{References}

1 Cao C, Wang R, Wang J, et al. Body mass index and mortality in chronic obstructive pulmonary disease: a meta-analysis. PLoS ONE 2012; 7: e43892.

2 Spelta F, Fratta Pasini AM, Cazzoletti L, et al. Body weight and mortality in COPD: focus on the obesity paradox. Eat Weight Disord 2018; 23: 15-22.

3 Morse SA, Gulati R, Reisin E. The obesity paradox and cardiovascular disease. Curr Hypertens Rep 2010; 12: $120-126$.

4 Akin I, Nienaber CA. 'Obesity paradox' in coronary artery disease. World J Cardiol 2015; 7: 603-608.

5 Park J, Ahmadi SF, Streja E, et al. Obesity paradox in end-stage kidney disease patients. Prog Cardiovasc Dis 2014; 56: 415-425.

6 Flegal KM, Kit BK, Orpana $\mathrm{H}$, et al. Association of all-cause mortality with overweight and obesity using standard body mass index categories: a systematic review and meta-analysis. JAMA 2013; 309: 71-82.

7 Global BMI Mortality C, Di Angelantonio E, Bhupathiraju S, et al. Body-mass index and all-cause mortality: individual-participant-data meta-analysis of 239 prospective studies in four continents. Lancet 2016; 388: 776-786.

8 Landbo C, Prescott E, Lange P, et al. Prognostic value of nutritional status in chronic obstructive pulmonary disease. Am J Respir Crit Care Med 1999; 160: 1856-1861.

9 Yin HL, Yin SQ, Lin QY, et al. Prevalence of comorbidities in chronic obstructive pulmonary disease patients: a meta-analysis. Medicine (Baltimore) 2017; 96: e6836.

10 Putcha N, Drummond MB, Wise RA, et al. Comorbidities and chronic obstructive pulmonary disease: prevalence, influence on outcomes, and management. Semin Respir Crit Care Med 2015; 36: 575-591.

11 Huiart L, Ernst P, Suissa S. Cardiovascular morbidity and mortality in COPD. Chest 2005; 128: 2640-2646.

12 Curkendall SM, DeLuise C, Jones JK, Jr, et al. Cardiovascular disease in patients with chronic obstructive pulmonary disease, Saskatchewan Canada cardiovascular disease in COPD patients. Ann Epidemiol 2006; 16: 63-70.

13 Vestbo J, Anderson JA, Brook RD, et al. Fluticasone furoate and vilanterol and survival in chronic obstructive pulmonary disease with heightened cardiovascular risk (SUMMIT):a double-blind randomised controlled trial. Lancet 2016; 387: 1817-1826.

14 Hankinson JL, Odencrantz JR, Fedan KB. Spirometric reference values from a sample of the general US population. Am J Respir Crit Care Med 1999; 159: 179-187.

15 Hankinson JL, Kawut SM, Shahar E, et al. Performance of American Thoracic Society-recommended spirometry reference values in a multiethnic sample of adults: the multi-ethnic study of atherosclerosis (MESA) lung study. Chest 2010; 137: 138-145.

16 Vestbo J, Anderson J, Brook RD, et al. The Study to Understand Mortality and Morbidity in COPD (SUMMIT) study protocol. Eur Respir J 2013; 41: 1017-1022.

17 WHO. Body mass index - BMI. http://www.euro.who.int/en/health-topics/disease-prevention/nutrition/ a-healthy-lifestyle/body-mass-index-bmi\# Date last updated: 2018.

18 Crim C, Calverley PMA, Anderson JA, et al. Pneumonia risk with inhaled fluticasone furoate and vilanterol in COPD patients with moderate airflow limitation: The SUMMIT trial. Respir Med 2017; 131: 27-34.

19 Guo Y, Zhang T, Wang Z, et al. Body mass index and mortality in chronic obstructive pulmonary disease: a dose-response meta-analysis. Medicine (Baltimore) 2016; 95: e4225. 

pulmonary disease. Am J Respir Crit Care Med 1996; 153: 961-966.

21 Yang L, Zhou M, Smith M, et al. Body mass index and chronic obstructive pulmonary disease-related mortality: a nationally representative prospective study of 220,000 men in China. Int J Epidemiol 2010; 39: 1027-1036.

22 Schols AM, Slangen J, Volovics L, et al. Weight loss is a reversible factor in the prognosis of chronic obstructive pulmonary disease. Am J Respir Crit Care Med 1998; 157: 1791-1797.

23 Schols AM, Ferreira IM, Franssen FM, et al. Nutritional assessment and therapy in COPD: a European Respiratory Society statement. Eur Respir J 2014; 44: 1504-1520.

24 Chailleux E, Laaban JP, Veale D. Prognostic value of nutritional depletion in patients with COPD treated by long-term oxygen therapy: data from the ANTADIR observatory. Chest 2003; 123: 1460-1466.

25 Hallin R, Gudmundsson G, Suppli Ulrik C, et al. Nutritional status and long-term mortality in hospitalised patients with chronic obstructive pulmonary disease (COPD). Respir Med 2007; 101: 1954-1960.

26 Lainscak M, von Haehling S, Doehner W, et al. Body mass index and prognosis in patients hospitalized with acute exacerbation of chronic obstructive pulmonary disease. J Cachexia Sarcopenia Muscle 2011; 2: 81-86.

27 Speizer FE, Fay ME, Dockery DW Jr, et al. Chronic obstructive pulmonary disease mortality in six US cities. Am Rev Respir Dis 1989; 140: S49-S55.

28 Prescott E, Almdal T, Mikkelsen KL, et al. Prognostic value of weight change in chronic obstructive pulmonary disease: results from the Copenhagen City Heart Study. Eur Respir J 2002; 20: 539-544.

29 Young T, Palta M, Dempsey J, et al. The occurrence of sleep-disordered breathing among middle-aged adults. N Engl J Med 1993; 328: 1230-1235.

30 Ge X, Han F, Huang Y, et al. Is obstructive sleep apnea associated with cardiovascular and all-cause mortality? PLOS ONE 2013; 8: e69432.

31 McNicholas WT. COPD-OSA overlap syndrome: evolving evidence regarding epidemiology, clinical consequences, and management. Chest. 2017; 152: 1318-1326.

32 Guerra S, Sherrill DL, Bobadilla A, et al. The relation of body mass index to asthma, chronic bronchitis, and emphysema. Chest 2002; 122: 1256-1263.

33 Schembri S, Anderson W, Morant S, et al. A predictive model of hospitalisation and death from chronic obstructive pulmonary disease. Respir Med 2009; 103: 1461-1467.

34 Lambert AA, Putcha N, Drummond MB, et al. Obesity is associated with increased morbidity in moderate to severe COPD. Chest 2017; 151: 68-77.

35 Dixon AE, Lundblad LK, Suratt BT. The weight of obesity on lung health. Pulm Pharmacol Ther 2013; 26: 403-404.

36 Calverley PM, Anderson JA, Celli B, et al. Salmeterol and fluticasone propionate and survival in chronic obstructive pulmonary disease. N Engl J Med 2007; 356: 775-789.

37 Verberne LDM, Leemrijse CJ, Swinkels ICS, et al. Overweight in patients with chronic obstructive pulmonary disease needs more attention: a cross-sectional study in general practice. NPJ Prim Care Respir Med 2017; 27: 63.

38 Mannino DM, Thorn D, Swensen A, et al. Prevalence and outcomes of diabetes, hypertension and cardiovascular disease in COPD. Eur Respir J 2008; 32: 962-969.

39 Celli BR, Cote CG, Marin JM, et al. The body-mass index, airflow obstruction, dyspnea, and exercise capacity index in chronic obstructive pulmonary disease. N Engl J Med 2004; 350: 1005-1012.

40 WHO Expert Consultation. Appropriate body-mass index for Asian populations and its implications for policy and intervention strategies. Lancet 2004; 363: 157-163.

41 Stokes A, Preston SH. Smoking and reverse causation create an obesity paradox in cardiovascular disease. Obesity (Silver Spring) 2015; 23: 2485-2490.

42 Banack HR, Kaufman JS. The obesity paradox: understanding the effect of obesity on mortality among individuals with cardiovascular disease. Prev Med 2014; 62: 96-102.

43 Sperrin M, Candlish J, Badrick E, et al. Collider bias is only a partial explanation for the obesity paradox. Epidemiology 2016; 27: 525-530.

44 Khakban A, Sin DD, FitzGerald JM, et al. The projected epidemic of chronic obstructive pulmonary disease hospitalizations over the next 15 years. A population-based perspective. Am J Respir Crit Care Med 2017; 195: 287-291.

45 WHO. Obesity and overweight. www.who.int/news-room/fact-sheets/detail/obesity-and-overweight Date last updated: 2018. 